\title{
Open Rotor Noise Prediction Methods at NASA Langley-A Technology Review
}

\author{
F. Farassat, AIAA Fellow \\ NASA Langley Research Center, Hampton, Virginia \\ feri.farassat@nasa.gov \\ Mark H. Dunn, AIAA Senior Member \\ Consultant, Yorktown, Virginia \\ Mhd314@aol.com \\ Ana F. Tinetti, AIAA Senior Member \\ Consultant, Yorktown, Virginia \\ ana.f.tinetti@nasa.gov \\ Douglas M. Nark, AIAA Member \\ NASA Langley Research Center, Hampton, Virginia \\ Douglas.M.Nark@nasa.gov
}

\begin{abstract}
Open rotors are once again under consideration for propulsion of the future airliners because of their high efficiency. The noise generated by these propulsion systems must meet the stringent noise standards of today to reduce community impact. In this paper we review the open rotor noise prediction methods available at NASA Langley. We discuss three codes called ASSPIN (Advanced Subsonic-Supersonic Propeller Induced Noise), FW - $\mathrm{H}_{\mathrm{pds}}$ (Ffowcs Williams-Hawkings with penetrable data surface) and the FSC (Fast Scattering Code). The first two codes are in the time domain and the third code is a frequency domain code. The capabilities of these codes and the input data requirements as well as the output data are presented. Plans for further improvements of these codes are discussed. In particular, a method based on equivalent sources is outlined to get rid of spurious signals in the $\mathrm{FW}-\mathrm{H}_{\mathrm{pds}}$ code.
\end{abstract}




\section{1- Introduction}

The high fuel prices of recent years have caused the operating cost of the airlines to soar. In an effort to bring down the fuel consumption, the major aircraft engine manufacturers such as GE, Rolls-Royce and CFM International are now taking a fresh look at open rotors for the propulsion of future airliners. Open rotors, also known as propfans or unducted fans, can offer up to 30 per cent improvement in efficiency compared to high bypass engines of 1980 vintage currently in use in most civilian aircraft. The lower fuel consumption of open rotors also contributes to the reduction of carbon emission into the atmosphere by airliners. Open rotor propulsion system can, therefore, be considered a Green engine. The single and contra-rotating open rotors are both under consideration for powering future aircraft. An example of a contra-rotating open rotor is shown in Figure 1 below.

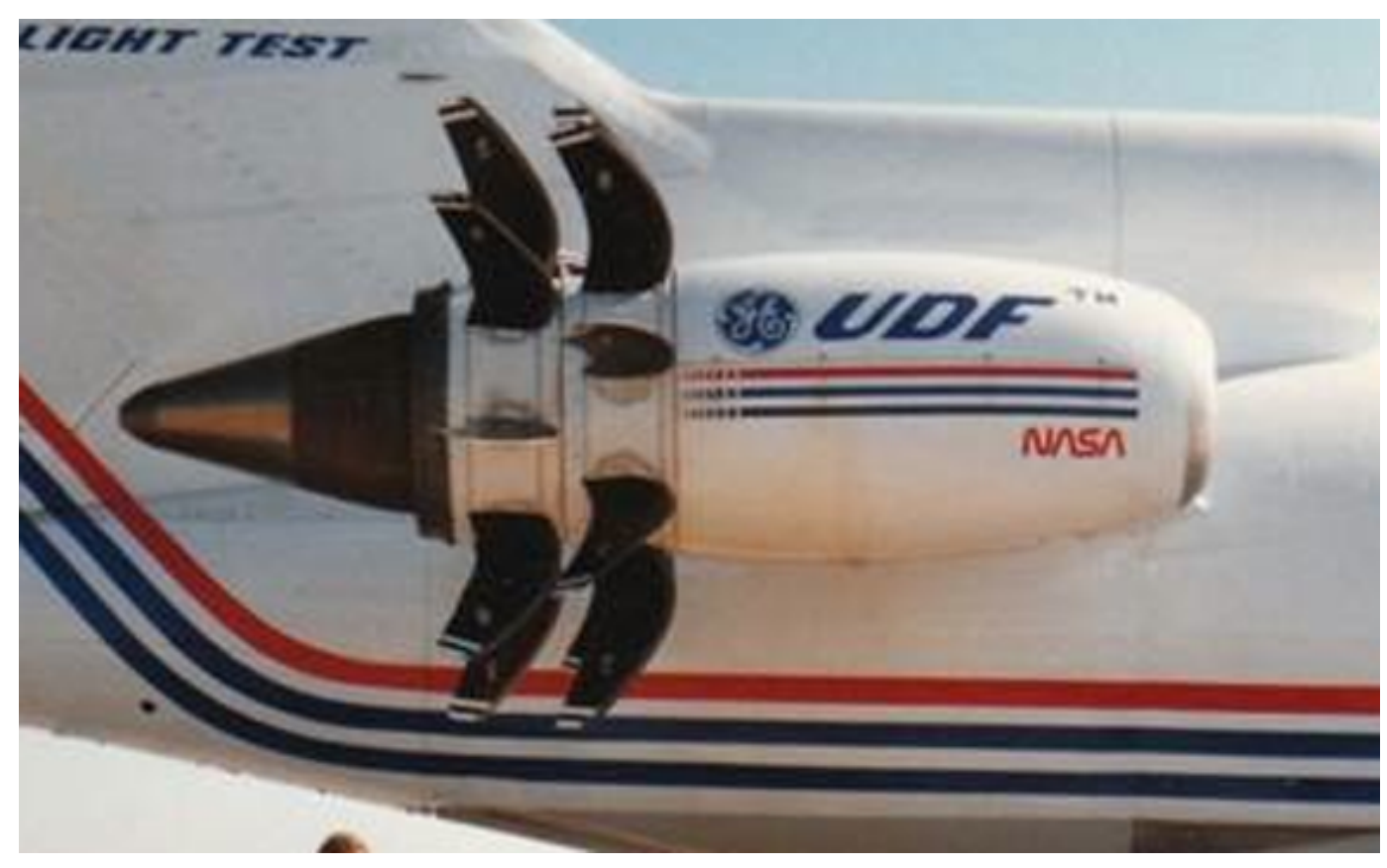

Figure 1- An example of contra-rotating open rotor design by GE

Open rotors operate at transonic to supersonic helical tip speeds that can go as high as Mach 1.3. The noise of these propulsion systems can cause both passenger and community concerns. The ability to predict the noise of open rotors at the design stage and to reduce the noise to an acceptable level are, therefore, of great importance to engine manufacturers. In 1980s, a comprehensive study of open rotors by NASA and the U.S. aircraft engine industry was carried out involving theory development, model and full scale tests. An impressive array of technology development in aeroelasticity, composite materials, mechanical design, aerodynamics and aeroacoustics resulted from this study. A large number of technical reports and publications in open literature were written by the engineers and researchers involved in this effort. These reports and publications are of great value to those involved in the resurgence of interest in open rotors around the world. 
NASA Langley researchers have contributed significantly to the development of aeroacoustic technology of open rotors. The present authors feel that it is appropriate at this time to present the current noise prediction technology at Langley and review the input data requirements, strengths and limitations of each method as well as the associated problems in need of attention by the researchers. These are the aims of the present paper.

In Section 2, we present a brief history of research on the aeroacoustics of rotating blade machinery at Langley Research Center. In Section 3, we discuss the available noise prediction codes for open rotors developed at NASA Langley and their capabilities. In particular, we briefly talk about the two useful formulations used for the computation of noise from subsonic and supersonic surfaces. Here we discuss the open rotor noise prediction codes ASSPIN and one based on Ffowcs Williams-Hawkings equation with penetrable data surface $\left(\mathrm{FW}-\mathrm{H}_{\mathrm{pds}}\right)$. The scattering of sound from surfaces near the rotor are calculated using the fast scattering code (FSC) which is also discussed in this section. Plans for further improvements of these codes are given in Section 4. Here we propose a method based on equivalent sources to establish the null field inside the data surface to get rid of the spurious signals in the $\mathrm{FW}-\mathrm{H}_{\mathrm{pds}}$ code.

\section{2- A Brief History of Research on the Aeroacoustics of Rotating Blade Machinery at Langley}

Langley has been in the forefront of research on aircraft noise generation and prediction since the 1930's [S1]. Some of the early researchers in this subject at Langley were Deming, Garrick, Watkins, Hubbard and Maglieri. This research was aided greatly with the introduction of the high speed digital computers in the 1960's that were used both in acoustic experiments as well as in the development of noise prediction codes. About the same time, the pace of research in the field of aeroacoustics in universities, industry and government agencies accelerated due to the public objection to aircraft noise both in the cabin and around the airports. Modern digital computers have made it possible to use advanced mathematical models to study the acoustics of propulsion systems with realistic geometry and operating conditions. NASA scientists and engineers have contributed significantly to aircraft noise reduction both by theory development and the use experimental methods.

In what follows, we will discuss the history of theoretical model development at Langley that the author was involved in the period 1975 to present. We will confine ourselves to subjects of relevance to aircraft with open rotors as their propulsion system. This would also involve the calculation of installation effects and the noise foot prints at various flight conditions.

The introduction of the concept of the acoustic analogy (AA) by Lighthill in 1952 [S2] was one of the most important advances in aeroacoustics which has resulted in current high level of aircraft noise prediction technology. In 1969, Ffowcs Williams and Hawkings presented an extension of Lighthill's jet noise equation to the noise from turbulence in the presence of moving surfaces appropriate for studying the acoustics of rotating machinery- helicopter rotors, propellers, fans and open rotors [S3]. This extension is known as the Ffowcs WilliamsHawkings (FW-H) equation.

Let a moving surface be described implicitly by $f(\boldsymbol{x}, t)=0$ such that $\nabla \mathrm{f}=\boldsymbol{n}, \boldsymbol{n}$ is the unit outward normal. This assumption implies that $f>0$ outside the moving surface (see Figure 2). 


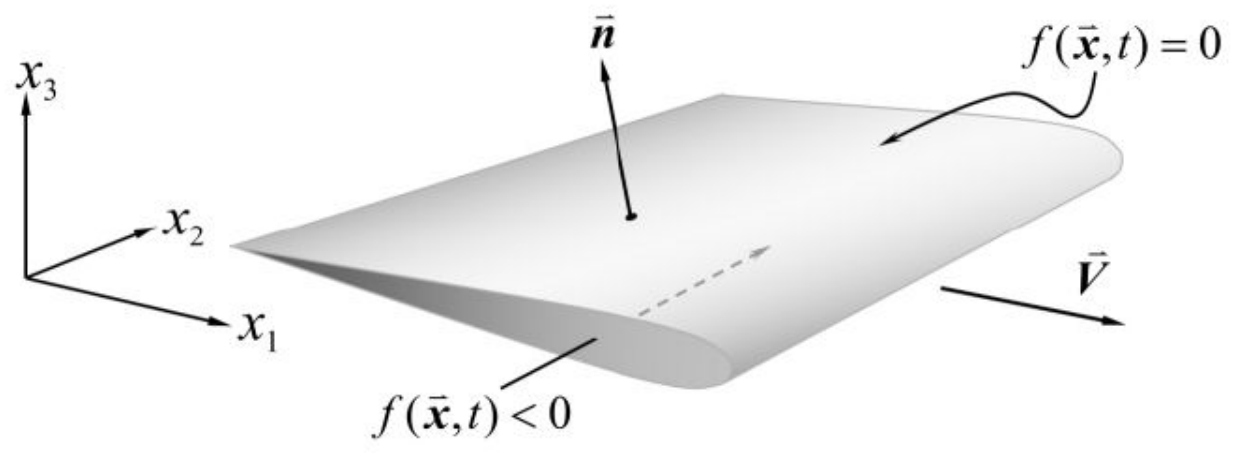

Figure 2- The definition of the moving surface implicitly as $f(x, t)=0$. Note that $\nabla f=n$ where $n$ is the unit outward normal to the surface.

The Ffowes Williams- Hawkings (FW-H) equation is

$$
\square^{2} p^{\prime}=\frac{\partial}{\partial t}\left[\rho_{0} v_{n} \delta(f)\right]-\frac{\partial}{\partial x_{i}}\left[p n_{i} \delta(f)\right]+\frac{\partial^{2}}{\partial x_{i} \partial x_{j}}\left[H(f) T_{i j}\right]
$$

Here and elsewhere in the paper, we will use the summation convention on the repeated index. In this equation $\square^{2}$ is the wave operator in three dimensional space. Also $p^{\prime}=c^{2} \rho^{\prime}=c^{2}\left(\rho-\rho_{0}\right)$, $c$ and $\rho_{0}$ are the speed of sound and density in the undisturbed medium, respectively. Note that $p^{\prime}$ can only be interpreted as the acoustic pressure if $\rho^{\prime} / \rho_{0}<<1$. The symbols $v_{n}, p$ and $T_{i j}=\rho u_{i} u_{j}-\sigma_{i j}+\left(p^{\prime}-c^{2} \rho^{\prime}\right) \delta_{i j}$ are the local normal velocity of the surface, the local gage pressure on the surface (in fact $p-p_{0}$ ), and the Lighthill stress tensor, respectively. In the definition of the Lighthill stress tensor, $\sigma_{i j}$ is the viscous stress tensor and $\delta_{i j}$ is the Kronecker delta. The Heaviside and the Dirac delta functions are denoted $H(f)$ and $\delta(f)$, respectively. In the second term on the right of eq. (1), we have neglected the viscous shear force over the blade surface acting on the fluid.

The three inhomogeneous source terms on the right of Eq. (1) are known as the thickness, loading and quadrupole sources, respectively. Note that the thickness and loading sources are surface sources while the quadrupole source is regarded as a volume source although it can be analytically broken into volume and surface sources [21, 23, 27, 31,36]. This latter point of view can explain several (old and new) mechanisms of noise generation in rotating blades some of which has not been studied in detail, e.g., flapping wakes in the vicinity of trailing edge. 
We note that we have artificially converted a nonlinear problem of noise generation by a moving surface to a linear problem by using the acoustic analogy. All the nonlinearities are lumped into the Lighthill stress tensor which is assumed known from near field aerodynamic calculations. When we started working on helicopter and propeller noise in the early seventies, because of the limitations of digital computers, the most we could expect from aerodynamic calculations was the blade surface pressure. For this reason, using some physical reasoning, we neglected the quadrupole volume sources in FW-H equation and concentrated on development of formulations for the prediction of thickness and loading noise. Later on, as computers became more powerful, we included quadrupoles in our noise prediction. There was, however, another theoretical advance which led to the use of purely surface sources to which we will turn next.

It was Ffowcs Williams himself who proposed to use a penetrable (porous or permeable) data surface to account for nonlinearities in the vicinity of a moving surface. We again assume that the penetrable surface defined by $f(\boldsymbol{x}, t)=0$ and the fluid velocity is denoted by $\boldsymbol{u}$. The $\mathbf{F W}-\mathbf{H}$ equation for penetrable (permeable, porous) data surface, $\mathbf{F W}-\mathrm{H}_{\mathrm{pd}}$, is:

$$
\square^{2} c^{2} \rho^{\prime} \equiv \square^{2} p^{\prime}=\frac{\partial}{\partial t}\left[\rho_{0} U_{n}\right] \delta(f)-\frac{\partial}{\partial x_{i}}\left[L_{i} \delta(f)\right]+\frac{\partial^{2}}{\partial x_{i} \partial x_{j}}\left[T_{i j} H(f)\right]
$$

We have used the following notations in the above equation:

$$
\begin{aligned}
& U_{n}=\left(1-\frac{\rho}{\rho_{0}}\right) v_{n}+\frac{\rho u_{n}}{\rho_{0}} \\
& L_{i}=p \delta_{i j} n_{j}+\rho u_{i}\left(u_{n}-v_{n}\right)
\end{aligned}
$$

where $\delta_{i j}$ is the Kronecker delta. As in the case of eq. (1), in the first term on the right of eq. (4), we have neglected the viscous shear force over the data surface acting on the fluid exterior to the surface. The philosophy behind using $\mathrm{FW}-\mathrm{H}_{\mathrm{pds}}$ is to locate the data surface $f=0$ to enclose a moving surface, in such a way that all quadrupoles producing non-negligible noise are included within this surface. Therefore, no volume integration of the quadrupoles outside the data surface is necessary. High resolution CFD calculation is performed in the near field region (including turbulence simulation if broadband noise prediction is required). The data surface used for the acoustic calculation should be located within the region of high resolution CFD computation. As discussed in Section 3, the optimal location of the data surface, particularly when vortices cross the surface, is still the subject of research. One would like this surface to be as small as possible, because of the computer intensive nature of aerodynamic and turbulence simulation that require fine grid sizes and small time steps.

We have developed several equivalent solutions of the FW-H equation in the time domain (called formulations in this paper) at NASA Langley that are used to develop two efficient codes for the prediction of the noise of rotating machinery. In the next section we present a discussion of these formulations, computer codes based on them and their capabilities. Note that the Fast Scattering Code (FSC) does not depend on these formulations but is included in the next section because we will find it useful for open rotor noise prediction when scattering of the generated noise by fuselage and wing surfaces becomes important. 


\section{3- Noise Prediction Codes for Open Rotors Developed at NASA Langley and Their Capabilities}

The first author has derived several solutions of the FW-H equation that are useful for efficient numerical computation of the noise of rotating blades. We mention here three formulations in the time domain valid in the near and far fields that include only the thickness and loading sources of the FW-H equation. In chronological order, these are:

1- Formulation $1[1,8,52]$ : This was developed for surfaces moving at subsonic motion if used with the Doppler singularity. It is valid for surfaces moving at transonic and supersonic speeds if at no time during the emission process the condition $M_{r}=1$ occurs and the collapsing sphere form of the formulation is utilized [1]. Here $M_{r}$ is the Mach number of the source in the radiation direction. Note that in this section, the Mach number is always based on the speed of sound in the undisturbed medium. In the case of transonic and supersonic speeds, the multiple emission times of the source must be accounted for in the acoustic calculation. Formulation 1 is the simplest of our three formulations distinguished by an observer time derivative before one of its two surface integrals. This time derivative must be evaluated numerically which can be a source of numerical error.

2- Formulation 1A [7-9, S4, 52]: This result was obtained by taking the observer time derivative of Formulation 1 inside the integral analytically and, thus, eliminating the need for taking the derivative numerically. Although, in principle, this result can be obtained by elementary calculus (not recommended), the simplest method of deriving it is using an identity of generalized functions for the free space Green's function of the wave equation at the beginning of the derivation [8]. An immediate consequence of eliminating the observer time derivative of Formula tion 1 is the increase in the complexity of the formula and the increase in the order of the Doppler singularity from $\left(1-M_{r}\right)^{-1}$ to $\left(1-M_{r}\right)^{-3}$. The increase in the complexity of the formulation does not cause any concern for numerical implementation on the computer. But the increase in the order of the singularity increases the sensitivity of the result near $M_{r}=1$. However, in practice, we must switch to Formulation 3 in the acoustic code when this situation occurs. The conditions for the validity of Formulation 1A are similar to Formulation 1 and is used in the forms with Doppler singularity (subsonic sources) as well as collapsing sphere (transonic and supersonic sources). An important use of Formulation 1A is in the acoustic code based on the $\mathrm{FW}-\mathrm{H}_{\mathrm{pds}}$ equation.

Formulation 3 [13, 16, 17, 20]: This complicated result is very difficult to derive and requires advanced knowledge of differential geometry, general tensor analysis and generalized functions. The formulation is valid at all range of the speed of the source surface-subsonic, transonic and supersonic. However, because of its complexity, it is recommended to use it for the parts of the surface for which the condition $M_{r}=1$ occurs. For blades with sharp leading and trailing edges in the supersonic region of the blade and properly designed sweep, no singularities should appear in the acoustic pressure when this formulation is used. Otherwise, one can expect the integrable logarithmic singularity in the acoustic pressure [22, 27]. 
An explanation of why Formulation 3 is so complicated is given in [46]. An important test of this formulation is to compare the predicted acoustic pressure signatures and spectra from a subsonic rotating blade exclusively from Formulations $1 \mathrm{~A}$ and 3 under identical input data. This computation has been performed at NASA Langley, documented but not published. The agreement of the predicted results from the two formulations was excellent for both the thickness and loading noise. Furthermore, this agreement also verified that both these formulations were coded correctly in ASSPIN.

Some old and obsolete NASA Langley acoustic codes used Formulation 1 for high speed propellers [6]. We currently use only Formulations 1A and 3 in our noise prediction codes such as ASSPIN discussed in the next section. The best article to read about how to implement these formulations most efficiently to predict the noise of rotating blade machinery is [20].

We now turn to the description of two computer codes for open rotor noise prediction. Note that our codes are valid for an observer in the near and far fields. The third code we discuss below is the Fast Scattering Code (FSC) which is recommended for the prediction of the effect of the scattering of the open rotor noise by fuselage and wings of an aircraft. This phenomenon includes the important shielding effect of noise by the rigid surfaces of the aircraft known also as the installation effect.

\section{1- Advanced Subsonic-Supersonic Propeller Induced Noise (ASSPIN) Code}

This code was developed in mid-nineteen eighties originally for a single row of open rotors known as propfans that operated at supersonic tip speed at cruise condition $[13,16,17,20]$. It can also calculate the noise of a contra-rotating propeller with equal number of blades in each row. However, the present code can form the core of a much more capable open rotor noise prediction code by the addition of pre- and post-processors. There is an excellent Users Manual written by Dunn and Tarkenton [S5]. This code uses Formulation 1A and 3 in such a way that the latter formulation is used for panels on the blades with near sonic speed. Farassat, Padula and Dunn [20] have described the structure and the algorithms of ASSPIN in great detail with some comparison of the predicted and measured acoustic data for propfans. Other publications of Langley with more examples of application of the code are [30, 34, 35]. One of the most significant tests of ASSPIN was against the frequency domain code of Donald B. Hanson with identical blade geometry, operating conditions and blade aerodynamics. The results with good agreement were published in the same issue of the AIAA Journal in 1992 [35, S6]

The ASSPIN code was written in FORTRAN 77 and developed originally on a CDC-7600 mainframe computer of NASA Langley. It runs very efficiently on a modern scientific desktop computer. Noise footprint computations can be performed routinely in a matter of few hours and even the animation of the footprint during the takeoff condition can be simulated in a reasonable time. Other than the fact that the nonlinear effects are not included in this code, it is one of the most robust, accurate and verified codes in the time domain in U.S. and, to our best knowledge, in the world.

\subsection{1- Input Data to ASSPIN}

1- Hot blade geometry- several options are available to users

2- Number of blades in each row

3 - Inflow angle to the rotor axis

4- Unsteady blade surface pressure 


\subsection{2- Output Data From ASSPIN}

1- Acoustic pressure time history for a stationery observer with respect to the ground or moving with the aircraft at uniform speed

2- Acoustic pressure spectrum for an observer moving with the aircraft at uniform speed or the acoustic spectrum for contiguous segments of time for a stationary observer (nonperiodic time history).

\section{2- Ffowcs Williams-Hawkings with Penetrable Data Surface $\left(\mathrm{FW}-\mathrm{H}_{\mathrm{pds}}\right)$ Code}

It has been known since the early days of high speed propeller noise research that nonlinear propagation effects in the near field are important. To include the nonlinearities, as discussed in Section 1, the use of a prediction code based on the $\mathrm{FW}-\mathrm{H}_{\mathrm{pds}}$ is an obvious choice. Since all the commercial airliners will fly at subsonic cruise speed in the foreseeable future, Formulation $1 \mathrm{~A}$ is the appropriate solution of the $\mathrm{FW}-\mathrm{H}_{\mathrm{pds}}$ equation to use. For an aircraft in steady rectilinear flight (the most common situation of interest), there is a simple closed-form formula based on the Garrick triangle construction for the computation of the retarded time in the acoustic calculations. Thus, the development of a noise prediction code based on $\mathrm{FW}-\mathrm{H}_{\mathrm{pds}}$ equation using Formulation 1A for this case is a relatively simple task. Nark and Farassat have developed such a code at Langley and have used it for ducted fan noise prediction [50]. It can be used for open rotors with some additional pre- and post-processors.

When turbulence and wakes from rotors cross the data surface, spurious acoustic signals appear in the acoustic signature which reduce the accuracy of this method. We will discuss in Section 3 our plans to alleviate this shortcoming of the method.

\subsection{1- Input Data to $\mathrm{FW}-\mathrm{H}_{p d s}$ Code}

High resolution unsteady CFD data (static pressure, fluid density and velocity) on the data surface must be specified.

\subsection{2- Output Data From $\mathrm{FW}-\mathrm{H}_{p d s}$ Code}

1- Acoustic pressure time history for a stationery observer with respect to the ground or moving with the aircraft at uniform speed

2- Acoustic pressure spectrum for an observer moving with the aircraft at uniform speed or the acoustic spectrum for contiguous segments of time for a stationary observer (nonperiodic time history).

\section{3- The Fast Scattering Code (FSC)}

This code was developed at NASA Langley by Dunn and Tinetti based on the equivalent source method (ESM) [S7, S8]. The theory behind the FSC is explained well in these references. It is based on the equations of time harmonic, linearized acoustics and the ESM is used for solving an exterior Helmholtz equation as a boundary value (BV) problem for a surface moving at uniform rectilinear speed. The incident sound source, e.g., the open rotor noise, is Fourier analyzed and the FSC is then used to compute the scattered noise for each frequency component. The ESM is a much more efficient method of finding the scattered noise than other well known techniques such as the boundary element method (BEM). The advantage comes from the fact that in ESM one does not have to deal with singular integrals (as in the case of BEM) which require elaborate and time consuming algorithms for their evaluation. For this reason, the use of ESM in the scattering problem results in a simple and efficient code. 
The FSC has been used to study the shielding effect of the engine noise by a wedge shaped airframe for which some experimental acoustic data were available [S9]. It was found that the agreement between the measured and predicted acoustic data was good. It is clear from this example that the shielding effect of fuselage and wings can be an important method of aircraft engine noise control. This effect can only be studied and quantified by utilizing the FSC. Note that the FSC provides some simple models of incident engine noise.

The ESM requires the inversion of a large matrix whose size and memory requirement increase with frequency $\omega$. Typically, the memory needed for the code is proportional to $\omega^{4}$ and the computational time is proportional to $\omega^{6}$. The proportionality constants are functions of the scattering surface area. It can be shown that on today's scientific desktop computers with one processor, either the size of the scattering surface must be kept small or the incident frequency must be assumed to be low [S8]. Fast multipole method (FMM) can be used to increase the upper limit of the frequency for the same scattering surface by a factor of 3 to 4 [S10]. However, even with the use of FMM, one is not able to calculate the scattering of noise from a large aircraft, say the size of Boeing 777, and an incident frequency of $10 \mathrm{khz}$ on a scientific desktop computer. But the FSC has be parellelized to run on multiprocessor machines to achieve this goal.

The FSC is written in FORTRAN and can be operated in batch mode. Version 2.0 is written for a single processor. It can also be driven by a graphical user interface (GUI) written in $\mathrm{C}++$ based on WXWidgets. We now have two parallel versions of the FSC - v3.1 for shared memory platforms, and v3.2 for distributed memory machines. These versions work quite well, and will be delivered to NASA by the end of January 2009. They will be available to the general public after the invention disclosure has been filed and approved. FSC v3.1/3.2 require very little computer memory. As the result of the low memory usage, practically any scattering surface size/frequency of interest can be handled now. But the trade-off is computational time that can be extensive.

The FSC was developed for the UNIX and LINUX operating systems but it can also be adapted for Windows and Macintosh environments. A Users Manual is available for various versions of the code [S8].

We believe that FSC is the most advanced and efficient aeroacoustic code available today for computation of the scattering of incident sound by aircraft surfaces. With parallelization to run on multiprocessor machines, it can fully meet the needs of the aircraft and engine industry for product design, evaluation and noise reduction.

\subsection{1- Input Data to FSC}

1- Excitation frequency and freestream thermodynamic variables

2- Numerical parameters for determining the appropriate grid generation and solution strategies

3- The scattering surface geometries (wings, fuselages, nacelles) and liner admittances

4- Local flow variables (density, speed of sound, and Mach number vector). Code options include: a- no flow, b- uniform flow, c- FSC generated small perturbation compressible flow, and d- user supplied flow

5- Complex values of incident acoustic pressure and acoustic velocity at FSC requested locations in space and time. Code options for incident sound include: a- simple point monopole(s) and dipole(s), b- FSC generated engine noise from nacelle alone run, and c- results from external noise codes capable of producing FSC type inputs. 
6- Observer position(s): Specify arbitrary observer points or request field calculations on spheres, cylinders, rectangular volumes surrounding the scattering surface. An option for requesting take-off or flyover footprints is provided.

\subsection{1- Output Data From FSC}

Complex values of the instantaneous acoustic pressure, velocity and intensity at the desired observer positions or the noise footprint regions. Graphical presentation of the output is available in version 2.0 of the code.

\section{4- Plans for Further Improvements of the Codes}

It can be seen from the above presentation that Langley researchers have developed the aeroacoustic technology to study the open rotor noise generation and reduction. The available codes are able to meet much of the need of the aircraft and engine industry for product design, evaluation and noise control. We feel that there are areas that are in need of further improvements. We also feel that the aircraft and engine industry have specific problems of interest that may require further extensions of the capabilities of our codes. We are interested to learn of these problems. We present below some of our research and development plans which will increase the capabilities and usefulness of our codes.

\section{1- Plans for ASSPIN Code}

ASSPIN is in an advanced stage of development and we suggest that this code be used for studying free open rotor noise. The reason is that to use the FSC with ASSPIN output as the incident sound source, we must be able to calculate the gradient of the acoustic pressure on all the scattering surface. The most numerically efficient method of finding the gradient is by an analytic method. This can be done rather easily for Formulations 1 and 1A [54] but it is next to impossible for Formulation 3 because of its analytic complexity and the number of terms. However, since the ASSPIN code was developed in nineteen eighties, there is a need for upgrading some of its capabilities. We recommend the following improvements to the ASSPIN code:

1- Improvements of the blade geometry specification- The blade geometry of the modern open rotors is a complex three dimensional curved surface. We require the calculation of various curvatures of the surface to use in Formulation 3. This means that we need a surface specification with smooth second derivatives. This task was relatively easy when NACA 2D airfoils were used by some open rotor blade designers because analytic expressions for airfoil coordinates were available. However, today's blade designers use advanced airfoils optimized by CFD codes for their performance. We need to use sophisticated three dimensional blade surface specification, e.g., NURBS, which will give us surface curvature information for noise prediction. We have made some progress in this direction but more work needs to be done in this area. This feature will be added as a pre-processor to ASSPIN. 


\section{2- Upgrading ASSPIN to compute the noise of contra-rotating open rotors with unequal} blade numbers and geometry in each row- Currently, ASSPIN code can handle contra-rotating open rotors with equal number of blades on each row and identical geometry. To treat the general case of unequal number of blades on each row, the acoustic pressure signatures of the interaction tones must be computed. This involves changes to the observer time step and period specifications in ASSPIN code itself. Furthermore, the part of the code for the computation of the acoustic spectrum must be modified to account for the interaction tones. This feature will also give us the ability of predicting the noise of a contra-rotating open rotor with two rows of rotors with very different geometries (blade numbers and blade designs).

\section{2- Proposed Plans for $\mathbf{F W}-\mathrm{H}_{\mathrm{pds}}$ code}

We have not used this code for open rotor noise prediction and what we are proposing is all new and requires further research. However, for two reasons we feel that work on this methodology must proceed with urgency because of the important capabilities it will provide us. First, we can include the near field nonlinear propagation effects which can be important in noise prediction. Second, this is the only open rotor prediction method that can be linked easily to the FSC to study the shielding effect and noise footprint changes by scattering from fuselage and wings (see Subsection 4.3, Item 2). We, therefore, propose the following research plans:

1- Removal of spurious signals from the computed acoustic pressure signature when eddies and wakes cross the data surface- When turbulent eddies or the wakes from open rotors cross the data surface of the $\mathrm{FW}-\mathrm{H}_{\mathrm{pds}}$ code, spurious signals appear in the acoustic pressure signature. This is a major cause of concern for the accuracy of this method. We now outline here a method to alleviate the spurious signals. Our discussion refers to Figure 3 below. 


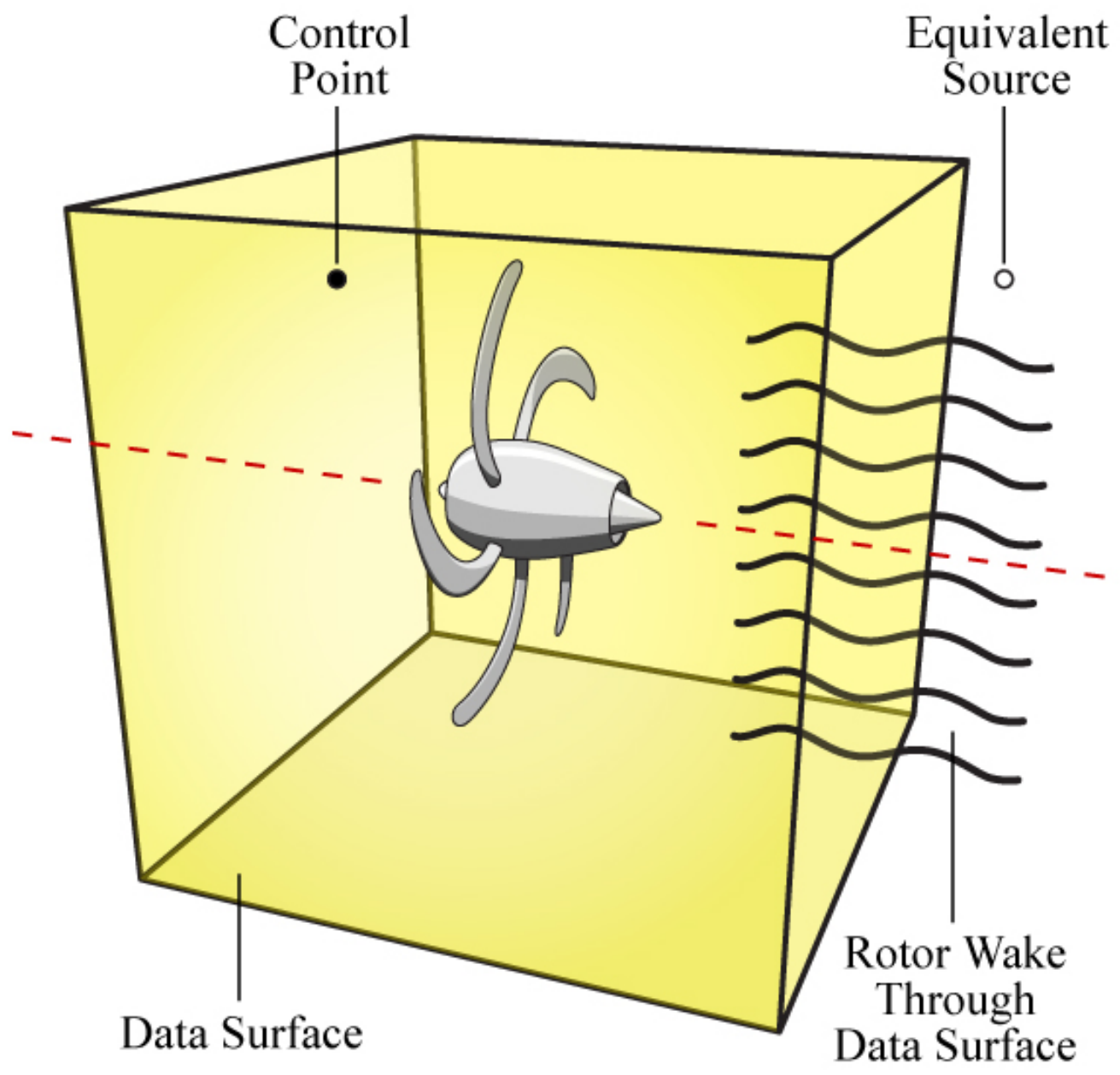

Figure 3- Sketch of the data surface for $\mathrm{FW}-\mathrm{H}_{\mathrm{pds}}$ code and the use of equivalent sources to generate the null field inside the data surface at control points. Here we show one equivalent source and one control point for simplicity.

We first note that in the application of this code, we specifically ignore the quadrupoles outside the data surface because specifying these sources is not practical. We only use surface sources in this method. When the rotor wakes cross the data surface, we have a fluctuating quadrupole field 
in the exterior of the data surface which generate the spurious signals. We have one important piece of information about the quadrupole field from the surface data. The sum of the contributions of the quadrupoles and the surface sources inside the data surface is identically zero (null field) for all time. Therefore, we can use some discrete sources (generally monopoles that we call equivalent sources) with unknown strengths in specified exterior or interior locations near the area of wake crossing to produce null field at specified control points inside the data surface. We must have, at a minimum, as many control points as the number of equivalent sources to be able to find the unknown strengths of the equivalent sources from a system of linear equations. Once the strengths of equivalent sources are found, the noise at any observer position in the exterior of the data surface is found from the surface sources as well as the equivalent sources and the spurious signals should disappear.

The problem of finding the source strengths is almost certainly ill-posed of the common variety seen, for instance, in solving the scattering problem using equivalent sources (as in FSC). The handling of such ill-posed problems is understood quite well and we do not expect undue difficulties to find the strengths of the equivalent sources.

2- Development of an algorithm to transfer CFD data to the data surface for acoustic calculations- This is an important recurring problem in aeroacoustics. We ask for high resolution CFD data for noise calculations and invariably the CFD grids do not coincide with the grids on the data surface for acoustic calculations. Using a surface generated by the CFD grids for acoustic calculations generally does not work because we need some surface geometry information (outward normal, etc.) that cannot be obtained easily from such a surface. The accurate extrapolation of high resolution CFD data to the data surface presents a challenging problem that needs to be solved to make the $\mathrm{FW}-\mathrm{H}_{\mathrm{pds}}$ code work satisfactorily. Such an algorithm must be implemented as a preprocessor for the code.

\section{3- Proposed Plans for the Fast Scattering Code (FSC)}

The FSC is in the process of intensive development at NASA Langley by Dunn and Tinetti. It has not been used for calculation of scattering of sound for an open rotor as the incident source of sound. However, we feel that the scattering of open rotor noise from aircraft fuselage and wings must be studied in the design stage for noise control. We propose the following developments and research plans for the FSC:

\section{1- Search for efficient and accurate method of storage and inversion of large and dense} matrices on multiprocessor machines- For multiprocessor machines, the selection of an efficient storage and the inversion method of large and dense matrices that ESM requires is a challenging problem. The accuracy of the results and the execution time are both dependent on the method of storage and inversion of the matrix. One criterion of the search for an algorithm is reaching a better balance between memory and time for the very large cases. This work will be performed by Dunn and Tinetti for NASA Langley. 
2- Development of a method for finding the pressure gradient of the incident sound at all points of scattering surface- To satisfy the boundary condition on the scattering surface (equality of the normal velocities of incident and scattered acoustic pressures), one needs to know the gradient of the incident sound. This is a very difficult problem. In the case of using ASSPIN for open rotor noise prediction, we have not been able to solve this problem yet. But for the case of $\mathrm{FW}-\mathrm{H}_{\mathrm{pds}}$ code used to simulate the incident sound for open rotors, we have been able to derive two analytic results for the acoustic pressure gradient based on Formulations 1 and 1A [54]. These are known as Formulations G1 and G1A with similar characteristics as Formulations 1 and $1 \mathrm{~A}$. Either result should be coded as a post-processor of the $\mathrm{FW}-\mathrm{H}_{\mathrm{pds}}$ code and thus provide the input data to the FSC.

\section{5- Concluding Remarks}

In this paper, we started with a brief review of the contributions of Langley researchers in the prediction of rotating blade machinery noise. We have then presented a discussion of the open rotor noise prediction codes developed at NASA Langley. Three codes ASSPIN, FW - $\mathrm{H}_{\mathrm{pds}}$ and the Fast Scattering Code (FSC) are discussed together with their capabilities. The required input data are pointed out and the output data are described for these codes. Finally, some plans for the improvements of these codes are presented. In particular, a method based on equivalent sources is outlined to get rid of spurious signals in the $\mathrm{FW}-\mathrm{H}_{\mathrm{pds}}$ code.

\section{Acknowledgment}

The first author has worked with Dr. Kenneth S. Brentner of Penn State on the problem of the spurious signals when using the $\mathrm{FW}-\mathrm{H}_{\mathrm{pds}}$ code.

\section{6- References}

\section{1- Main References- Publications of F. Farassat on Noise Prediction of Rotating Blade Machinery (Mainly Propellers and Open Rotors)}

Articles in boldface letters are significant publications of the first author on the subject of this paper.

1- F. Farassat: Theory of Noise Generation from Moving Bodies with an Application to Helicopter Rotors. NASA TR R-451, December 1975 
2- R. J. Pegg, B. Magliozzi and F. Farassat: Some Measured and Calculated Effects of Forward Velocity on Propeller Noise. Presented ASME Gas Turbine Conference and Products Show, Philadelphia, PA., March 27-31,1977. ASME Paper No. 77-GT-70

3- F. Farassat: Discontinuities in Aerodynamics and Aeroacoustics: The Concepts and Applications of Generalized Derivatives. Journal of Sound and Vibration, 55(2), 165-193, 1977

4- C. K. Barton, E. F. Daniels, F. Farassat and P. A. Nystrom: Analytical Noise Predictions: Appendix to paper entitled " Characteristicsof Propeller Noise on an Aircraft Fuselage and the Associated Interior Noise Transmission. Presented at the 5th AIAA Aeroacoustics Conference, Seattle, WA, March 12-14, 1979

5- F. Farassat and P. A. Nystrom: Letter to the Editor - Isom' sThickness Noise Formula for Rotating Blades with Finite Thickness at the Tip. Journal of Sound and Vibration, 72(4) $550-553,1980$

6- P. A. Nystrom and F. Farassat: A Numerical Technique for Calculation of the Noise of High Speed Propellers with Advanced Blade Geometry, NASA TP-1662, 1980

7- F. Farassat and G. P. Succi: A Review of Propeller Discrete Noise Prediction Technology with Emphasis on two Current Methods for Time Domain Calculations, Journal of Sound and Vibration, 71(3), 1980

8- F. Farassat: Linear Acoustic Formulas for Calculation of Rotating Blade Noise, AIAA Journal, 19(9), 1122-1130, September 1981

9- F. Farassat: Advanced Theoretical Treatment of Propeller Noise. Presented at von Karman Institute Lecture Series 1982-08, Brussels, Belgium, May 24-28, 1982

10- J. S. Mixson, F. Farassat, J. D. Leatherwood, R. Prydz, and J. D. Revell: .: Interior Noise Considerations for Advanced High-Speed Turboprop Aircraft. Journal of Aircraft, 20(9), 791-797, September 1983

11- F. Farassat, and G. P. Succi: The Prediction of Helicopter Rotor Discrete Frequency Noise, Vertica, 7(4), 309-320, 1983 
12- F. Farassat and R. M. Martin: A Note on the Tip Noise of Rotating Blades, Journal of Sound and Vibration, 86(3), 449-453, 1983

13- F. Farassat: The Prediction of the Noise of Supersonic Propellers in Time Domain-New Theoretical Results. Presented at the AIAA 8th Aeroacoustics Conference, Atlanta, GA, April 11-13, 1983, AIAA Paper No. 83-0743

14- F. Farassat: The Unified Acoustic and Aerodynamic Prediction of Advanced Propellers in the Time Domain. Presented at the AIAA/NASA 9th Aeroacoustics Conference, AIAA Paper No. 84-2303, Williamsburg, VA, October 1984

15- F. Farassat and M. K. Myers: Some Qualitative Results on the Thickness and Loading Noise of Rotating Blades. Journal of Sound and Vibration, 101(2), 1985, 262-266

16- F. Farassat: Theoretical Analysis of Linearized Acoustics and Aerodynamics of Advanced Supersonic Propellers. Invited lecture on Aerodynamics and Acoustics of Propellers. AGARD-CP-366, 1985

17- F. Farassat: The Prediction of the Noise of Advanced Propellers in the Time Domain. AIAA Journal, 24, 1986, 578-584

18- F. Farassat: The Ffowcs Williams-Hawkings Equation - Fifteen Years of Research, Aero and Hydro Acoustics, G. Comte-Bellot and J. E. Ffowcs Williams, editors, Springer Verlag, 1986, $175-180$

19- F. Farassat and M. K. Myers: Aerodynamics via Acoustics: Application of Acoustic Formulas for Aerodynamic Calculations. Presented at AIAA 10th Aeroacoustics Conference, Seattle, Washington, July 9-11, 1986

20- F. Farassat, S. L. Padula and M. H. Dunn: Advanced Turboprop Noise Prediction Based on Recent Theoretical Results. Journal of Sound and Vibration, 119(1),1987, 53-79

21- F. Farassat: Quadrupole Source in Prediction of the Noise of Rotating Blades - A New Source Description. Presented at AIAA 11th Aeroacoustics Conference, Sunnyvale, California, October 19-21, 1987, AIAA Paper 87-2675

22- M. K. Myers and F. Farassat: Structure and Propagation of Supersonic Singularities from Helicoidal Sources, Presented at AIAA 11th Aeroacoustics Conference, Sunnyvale, Cali- 
fornia, October 19-21, 1987, AIAA Paper 87-2676

23- F. Farassat and K. S. Brentner: The Uses and Abuses of the Acoustic Analogy in Helicopter Rotor Noise Prediction. Journal of the American Helicopter Society, 33, 1988, 29-36

24- F. Farassat and M. K. Myers: The Moving Boundary Problem for the Wave Equation: Theory and Application, Computational Acoustics - Algorithms and Applications, Vol. 2, D. Lee, R. L. Sternberg, and M. H. Schultz, Editors. North-Holland, 1988, 21-44

25- F. Farassat and M. K. Myers: Extension of Kirchhoff' sFormula to Radiation From Moving Surfaces, Journal of Sound and Vibration, 123(3), 1988, 451-460

26- F. Farassat, and M. K. Myers: High Speed Propeller Acoustics and Aerodynamics-A Boundary Element Approach. Proceedings of the International Symposium on Boundary Element Methods: Advances in Solid and Fluid Mechanics, East Hartford, CT, October 2-4, 1989

27- E. De Bernardis and F. Farassat: On the Possibility of Singularities in the Acoustic Field of Supersonic Sources when BEM is Applied to a Wave Equation. Proceedings of the International Symposium on Boundary Element Methods: Advances in Solid and Fluid Mechanics, East Hartford, CT, October 2-4, 1989. Appeared in the book: Boundary Element Methods in Engineering, B. S. Annigeri and K. Tseng (Eds.), 1990, Springer-Verlag

28- F. Farassat: The Shock Noise of High-Speed Rotating Blades- The Supersonic Problem. Presented at the Symposium of the International Association for Boundary Element Methods, October 15-19, 1990

29- F. Farassat and H. Tadghighi: Can Shock Waves on Helicopter Rotors Generate Noise? A Study of the Quadrupole Source. Presented at the Vertical Flight Technology for the 21st Century, 46th Annual Forum and Technology Display, American Helicopter Society, Washington, DC, May 21-23, 1990

30- M. H. Dunn and Farassat, F.: State-of-the-Art of High-Speed Propeller Noise Prediction - A Multidisciplinary Approach and Comparison with Measured Noise Data, presented at the AIAA 13th Aeroacoustics Conference, October 22-24, 1990, Tallahassee, FL, AIAA 90-3934

31- Farassat, F.; and Myers, M. K.: An Analysis of the Quadrupole Noise Source of High Speed Rotating Blades, Computational Acoustics - Scattering, Gaussian Beams, and 
Aeroacoustics, D. Lee, A. Cakmak, R Vichnevetsky, Editors, Vol. 2, 1990, 227-240

32- H. Tadghighi, R. Holz, and F. Farassat: Development of a Shock Noise Prediction Code for High Speed Helicopter Rotors- The Subsonically Moving Shock Case, Proceedings at the AHS 47th Annual Forum \& Technology Display, May 6-8, 1991, Phoenix, AZ

33- F. Farassat: On the Possibility of Strong Noise Generation by Shock Surfaces Attached to Rotating Blades. Presented at the Sixth International Symposium on Unsteady Aerodynamics, Aeroacoustics \& Aeroelasticity of Turbomachinery and Propellers, September 15-19, 1991, Notre Dame, IN

34- M. H. Dunn and F. Farassat: High Speed Propeller Noise Prediction-A Multidisciplinary Approach. AIAA Journal, 30(7), July 1992, 1716-1723

35- F. Farassat, M. H. Dunn and P. L. Spence: Advanced Propeller Noise Prediction in the Time Domain. AIAA Journal (Technical Note), 30(9), 1992, 2337-2340

36- F. Farassat and M. K. Myers: Aeroacoustics of High-Speed Rotating Blades: The Analyti cal Aspect, Computational Acoustics - Acoustic Propagation, D. Lee, R. Vichnevetsky and A. R. Robinson, North-Holland Publishing Company, Amsterdam, 1993, 117-148

37- F. Farassat: Introduction to Generalized Functions with Applications in Aerodynamics and Aeroacoustics. NASA TP-3428, 1994, Corrected Copy (April 1996)

38- F. Farassat and M. K. Myers: Line Source Singularity in the Wave Equation and Its Removal by Quadrupole Sources - A Supersonic Propeller Noise Problem. Structural Acoustics, Scattering and Propagation, J. E. Ffowcs Williams, D. Lee, and A. D. Pierce, editors, World Scientific, Singapore, 1994, 29-43

39- F. Farassat and M. K. Myers: The Kirchhoff Formula for a Supersonically Moving Surface, June 12-15, 1995, Munich, Germany, CEAS/AIAA Paper No. 95-062

40- F. Farassat: Generalized Functions and Kirchhoff Formulas, May 6-8, 1996, State College, PA, AIAA/CEAS Paper No. 96-1705

41- F. Farassat: The Kirchhoff Formulas for Moving Surfaces in Aeroacoustics- The Subsonic and Supersonic Cases, NASA Technical Memorandum 110285, 1996 
42- F. Farassat and K. S. Brentner: The Acoustic Analogy and the Prediction of the Noise of Rotating Blades. Theoretical and Computational Fluid Dynamics, 10(1-4), 1998, 155-170

43- F. Farassat, Kenneth S. Brentner and M. H. Dunn: A Study of Supersonic Surface Sources- The Ffowcs Williams-Hawkings Equation and the Kirchhoff Formula, AIAA 98-2375

44- Kenneth S. Brentner and F. Farassat: Analytical Comparison of the Acoustic Analogy and Kirchhoff Formulation for Moving Surfaces, AIAA Journal, 36(8), 1998, 1379-1386

45- F. Farassat and K. S. Brentner: Supersonic Quadrupole Noise Theory for High-Speed helicopter Rotors, Journal of Sound and Vibration, 218(3), 1998, 481-500

46- F. Farassat and Mark Farris: The Mean Curvature of the Influence Surface of Wave Equation With Sources on a Moving Surface, Analytical Methods in the Applied Sciences, 22, 1999, 1485-1503

47- F. Farassat: Acoustic Radiation From Rotating Blades - The Kirchhoff Method in Aeroacoustics, JSV, 239 (4), 2001, 785-800 (Philip Doak 80th Birthday Issue)

48- J. Casper and F. Farassat: Broadband Trailing Edge Noise Predictions in the Time Domain, Journal of Sound and Vibration, 271(1-2), 2004, 159-176

49- F. Farassat and J. Casper: Some Analytic Results for the Study of Broadband Noise Radiation from Wings, Propellers and Jets in Uniform Motion, International Journal of Aeroacoustics, 2(3-4), 2003, 335-350

50- Douglas M. Nark and F. Farassat: CDUCT-LaRC Status - Shear Layer Refraction and Noise Radiation, AIAA-2006-2587, 12th AIAA/CEAS Aeroacoustics Conference, May 8-10, 2006, Cambridge, Massachusetts

51- F. Farassat, Jay H. Casper, Ana F. Tinetti and M. H. Dunn: Airframe Noise Prediction by Acoustic Analogy:

Revisited, AIAA-2006-2564, 12th AIAA/CEAS Aeroacoustics Conference, May 8-10, 2006, Cambridge, Massachusetts

52- F. Farassat: Derivation of Formulations 1 and 1 A of Farassat, NASA-TM-2007-214853, March 2007 
53- Handbook Article- F. Bruce Metzger and F. Farassat, Aircraft Propeller Noise Sources, Prediction, and Control, Chapter 87 of Handbook of Noise and Vibration Control (Malcolm Crocker, Editor), John Wiley and Sons, 2007

54- Seongkyu Lee, Kenneth S. Brentner, F. Farassat and Philip J. Morris: Analytic Formulation and Numerical Implementation of an Acoustic Pressure Gradient Prediction, Journal of Sound and Vibration 319, 2009, 1200- 1221

\section{2- Supplementary References}

S1- F. Bruce Metzger: A Review of Propeller Noise PredictionMethodology 1919-1994, NASA Contractor Report 198156, June 1995

S2- M. J. Lighthill: On sound generated aerodynamically I. General theory. Proceedings of the Royal Society, A211, 1952, 564-587

S3- J. E. Ffowcs Williams and D. L. Hawkings: Sound Generation by Turbulence and Surfaces in Arbitrary Motion, Philosophical Transactions of the Royal Society, A264, 1969, 321-342

S4- Kenneth S. Brentner, Prediction of Helicopter Discrete Frequency Rotor Noise- A Computer Program Incorporating Realistic Blade Motions and Advanced Formulation, October 1986, NASA TM 87721

S5- M. H. Dunn and G. M. Tarkenton: Computational Methods in the Prediction of Advanced Subsonic and Supersonic Propeller Induced Noise- ASSPIN Users' Manual, NASA Contractor Report 4434, April 1992

S6- Donald B. Hanson: Direct Frequency Domain Calculation of Open Rotor Noise, AIAA Journal (Technical Note), 30(9), 1992, 2334-2337

S7- Mark H. Dunn and Ana F. Tinetti: Aeroacoustic Scattering Via The Equivalent Source Method, AIAA 2004-2937, 10th AIAA/CEAS Aeroacoustics Conference, May 10 - 12, 2004, Manchester, England

S8- Ana F. Tinetti, Mark H. Dunn and D. Stewart Pope: Fast Scattering Code (FSC) User' s Manual- Version 2.0, NASA/CR-2006-214510, October 2006

S9- Carl H. Gerhold, Lorenzo R. Clark, Mark H. Dunn and John Tweed: Investigation of acoustical shielding by a wedge-shaped airframe, Journal of Sound and Vibration, 294, 2006, 49-63

S10- Mark H. Dunn and Ana F. Tinetti: Application of Fast Multipole Methods to the NASA Fast Scattering Code, 14th AIAA/CEAS Aeroacoustics Conference, May 5-7, 2008, Vancouver, British Columbia, Canada 